\title{
MULHERES VÍTIMAS DE VIOLÊNCIA DOMÉSTICA ATENDIDAS PELO PROGRAMA MULHERES MIL DO INSTITUTO FEDERAL DE EDUCAÇÃO, CIÊNCIA E TECNOLOGIA DO MARANHÃO - CAMPUS CODÓ
}

\author{
WOMEN THAT ARE VICTIMS OF DOMESTIC VIOLENCE AND ASSISTED BY THE \\ PROGRAM MULHERES MIL OF THE INSTITUTO FEDERAL DE EDUCAÇÃO, \\ CIÊNCIA E TECNOLOGIA DO MARANHÃO - CAMPUS CODÓ
}

\section{A. B. SILVA ${ }^{1, *}$ e K. C. N. de OLIVEIRA ${ }^{2}$}

${ }^{1}$ Universidade Estadual do Sudoeste da Bahia, Departamento de Memória: Linguagem e Sociedade, Brasil

2 Universidade Estadual do Maranhão, Departamento de Humanas e Sociais, Brasil

\author{
ARTICLE INFO \\ Article history: \\ Received 2018-07-04 \\ Accepted 2018-10-15 \\ Available online 2018-10-31 \\ ${ }^{*}$ Autor correspondente: \\ E-mail: adriana.silva@ifma.edu.br
}

Palavras-chave: Mulheres. Violência doméstica. Educação. Cidadania. Vulnerabilidade.

Keywords: Women. Domestic violence. Education. Citizenship. Vulnerability.

RESUMO. O presente trabalho tem como objetivo precípuo descrever as experiências e vivências de mulheres vítimas de violência doméstica atendidas pelo Projeto Mulheres Mil no Instituto Federal de Educação, Ciência e Tecnologia do Maranhão (IFMA) - Campus Codó. O Programa Mulheres Mil constitui-se uma ferramenta educacional para o benefício de mulheres em situação de vulnerabilidade social e muitas dessas mulheres são vítimas de violência perpetrada por seus companheiros e/ou ex-companheiros. Estruturado em três eixos - Educação, Cidadania e Desenvolvimento Sustentável - o programa possibilita a inclusão social, por meio da oferta de formação focada na autonomia e na criação de alternativas para a inserção no mundo do trabalho, para que essas mulheres consigam melhorar a qualidade de suas vidas e de suas comunidades. Nessa perspectiva o IFMA -Campus Codó está desenvolvendo esta experiência viabilizando o ingresso e a permanência com êxito da população feminina das comunidades que ficam localizadas no entorno do Instituto Federal. O Projeto surge como uma possibilidade de aliar a educação ao trabalho, visando à diminuição de problemas sociais em comunidades de baixo índice de desenvolvimento humano e principalmente para amenizar o índice de violência contra a mulher e fomentar essa discussão no espaço educacional. O IFMA Campus Codó, aderiu ao Programa na Chamada Pública MEC/Setec - 06/2012, para atender mulheres em 
Cursos Básico de Qualificação Profissional. A relevância desta experiência está contida na problemática das minorias que estão à margem de políticas públicas compensatórias e reparadoras para a igualdade de gênero.

ABSTRACT. The main objective of this study is to describe the experiences of women that are victims of domestic violence, assisted by the Mulheres Mil project at the Instituto Federal de Educação, Ciência e Tecnologia do Maranhão (Ifma) - Campus Codó. The Mulheres mil Program is an educational tool for the benefit of women in situations of social vulnerability and many of these women are also victims of violence perpetrated by their loving partners and / or ex loving partners. Structured in three center lines - Education, Citizenship and Sustainable Development - the program provides the social inclusion, by the provision of training focused on autonomy and the creation of alternatives for insertion into the world of work, so that these women can improve the quality of their lives and their communities. From this perspective, the Ifma - Campus Codó is developing this experience, enabling the successful entry and stay of the female population of the communities located near the Instituto Federal. The Project emerges as a possibility of allying education to work, aiming at the reducing of social problems in communities with low human development index and mainly to soften the index of violence against women and to foment this discussion in the educational space. The Ifma - Campus Codó, joined the Program in the Chamada Pública (Public Call) MEC / Setec - 06/2012, to attend women providing Basic Professional Qualification Courses. The relevance of this experience is contained in the problem of minorities that are not contemplated by compensatory and reparatory public policies for gender equality.

\section{Introdução}

Os reflexos da violência contra a mulher praticada na ambiência doméstica atingem as esferas econômicas, afetiva e jurídica. Além de ser um grave problema social e de saúde pública, uma vez que afeta a integridade física e a saúde mental da mulher.

A "Convenção Interamericana para Prevenir, Punir e Erradicar a Violência contra a Mulher" (Convenção de Belém do Pará), assim define Violência: "qualquer ação ou conduta, baseada no gênero que cause morte, dano ou sofrimento físico, sexual ou psicológico à mulher, tanto no âmbito público ou privado" (ORGANIZAÇÃO DOS ESTADOS AMERICANOS, 1994, não paginado). O presente trabalho tem como finalidade abordar as experiências e vivências de mulheres vítimas de violência doméstica atendidas pelo Projeto Mulheres Mil no Instituto Federal de Educação, Ciência e Tecnologia do Maranhão e apresentado no VII Simpósio Internacional Trabalho, Relações de Trabalho, Educação e Identidade (SITRE), realizado em Belo Horizonte, capital do estado de Minas Gerais em maio de 2018.

O artigo intitulado "MULHERES VÍTIMAS DE VIOLÊNCIA DOMÉSTICA ATENDIDAS PELO PROGRAMA MULHERES MIL DO INSTITUTO FEDERAL DE EDUCAÇÃO, CIÊNCIA E TECNOLOGIA DO MARANHÃO - CAMPUS CODÓ”, ora apresentado é decorrente das experiências vivenciadas no âmbito profissional como Coordenadora do Programa Mulheres 
Mil ${ }^{1}$ no Instituto Federal de Educação, Ciência e Tecnologia do Maranhão (IFMA) - Campus Codó, experiência que considero fecunda por haver despertado e direcionado meus olhos para uma temática tão importante e carecedora de aprofundamento como esta, especialmente, por se tratar e abordar a questão da violência contra a mulher no espaço educacional.

O contato direto com mulheres vítimas de violência doméstica nos permitiu observar a partir de suas narrativas em sala de aula as diversas formas de expressão da violência sofridas por essas mulheres em seu cotidiano. Diante desse universo feminino tão enriquecedor e propício à pesquisa despertou o interesse pelo tema enquanto objeto de pesquisa. Este estudo é uma pesquisa do tipo exploratória ${ }^{2}$, desenvolvida com base na pesquisa qualitativa. A pesquisa qualitativa permite que os sujeitos tragam à tona o que pensam a respeito do que está sendo pesquisado. Quanto à população e aos sujeitos que foram pesquisados, destaca-se que a pesquisa abrange o Programa Mulheres Mil, vinculado ao Centro de Referência Especializado da Assistência Social ${ }^{3}$ (Creas), localizado no município de Codó-MA.

A população pesquisada compreendeu 7 (sete) mulheres, mães de crianças e/ou adolescentes atendidas pelo Programa Mulheres Mil. Para fins deste trabalho, iremos enfocar somente a perspectiva das mulheres. Para a realização da coleta de dados com as mulheres, foram realizadas entrevistas semiestruturadas com base em um roteiro de entrevistas. Foi apresentado um termo de consentimento livre e esclarecido a essas mulheres, o termo teve como finalidade esclarecer-Ihes acerca da importância de sua participação na pesquisa, bem como sua finalidade no estudo.

${ }^{1}$ O Mulheres Mil está inserido no conjunto de prioridades das políticas públicas do Governo do Brasil, especialmente nos eixos de promoção da equidade, igualdade entre sexos, combate à violência contra a mulher e acesso à educação. O Programa Mulheres Mil é decorrente da cooperação internacional Brasil - Canadá - Promoção de Intercâmbio de Conhecimento para a Promoção de Equidade (Pipe), e estruturado a partir dos conhecimentos desenvolvidos pelos Community Colleges canadenses em suas experiências de promoção da eqüidade, de atendimento às populações desfavorecidas e do desenvolvimento e aplicação do Sistema de Avaliação e Reconhecimento de Aprendizagem Prévia (Arap). No Brasil, o Sistema foi adaptado a nossa realidade, prevendo "a sistematização de um plano educacional que possibilita a elevação da escolaridade com curso de formação profissional" (BRASIL, 2011a, p. 3). Ousado e inédito na Rede Federal de Educação Profissional e Tecnológica em todo o Brasil, o Mulheres Mil trouxe o desafio de trabalhar com recortes de exclusão: mulheres jovens e adultas, em situação de vulnerabilidade econômica e social, a maioria com baixa escolaridade e à margem do mundo do trabalho (ROSA, 2011).

${ }^{2}$ A pesquisa foi exploratória, por proporcionar uma maior familiaridade com o problema, tornando-o mais visível, além de ser bastante flexível (GIL, 2010).

${ }^{3} \mathrm{O}$ Creas é composto por uma equipe multidisciplinar, formada por assistentes sociais, psicólogos, advogado, pedagogas e educadores sociais, que desenvolvem os seguintes serviços: Serviço de Proteção e Atendimento Especializado a Famílias e Indivíduos (Paefi); Serviço Especializado em Abordagem Social, e Serviço de Proteção Social a Adolescentes em Cumprimento de Medida Socioeducativa de Liberdade Assistida (LA) e de Prestação de Serviços à Comunidade (PSC); conforme a Resolução n109/09 - MDS Tipificação Nacional de Serviços Socioassistenciais (CONSELHO NACIONAL DE ASSISTÊNCIA SOCIAL, 2009). O Creas está localizado na Rua Honorino Silva, 733, Bairro São Francisco, Codó-MA. 
Os nomes das participantes foram trocados para a preservação de suas imagens. Teve-se como critério de inclusão da amostra: mulheres vítimas de violência nas relações conjugais; que estavam frequentando o Programa Mulheres Mil regularmente; e que demonstraram interesse em participar da pesquisa narrando suas histórias de violência. $A$ relevância deste estudo é evidenciada nesta pesquisa ao tratar sobre a temática da violência contra a mulher que constitui-se ainda como uma violação aos direitos humanos e um obstáculo para a cidadania de milhares de mulheres (SAFFIOTI, 1997).

\section{O Programa Mulheres Mil}

Constituídos pela Lei Federal n 11.892/2008, os Institutos Federais de Educação,

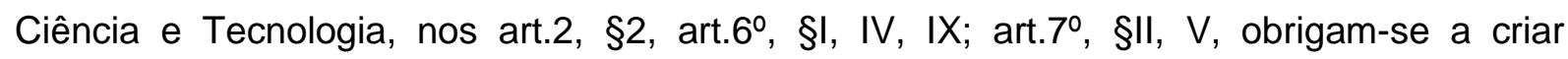
mecanismos para a promoção do acesso das populações tradicionalmente afastadas da possibilidade de inclusão ao conhecimento, à tecnologia e à inovação, gerados nos Institutos Federais, sendo-lhes atribuídas as responsabilidades de promover a educação profissional e tecnológica para jovens e adultos, por meio da Formação Inicial e Continuada, atendendo as demandas sociais e peculiaridades regionais (BRASIL, 2008). O Programa Nacional Mulheres Mil, instituído pela Portaria no 1.015, de 21 de julho de 2011, vem a ser um desses mecanismos de atendimento à formação profissional e tecnológica, em consonância com a elevação da escolaridade de mulheres em situação de vulnerabilidade social. O Programa deve ser ofertado por Instituições de Educação Profissional e Tecnológica e permite parceria com instituições de ensino regular (BRASIL, 2011b).

Partindo-se do princípio de se trabalhar com as mulheres, tornando-as protagonista na busca pela sua cidadania, o Projeto Mulheres Mil propicia a estas mulheres a possibilidade de produzir mudanças significativas em suas vidas, no que concerne ao seu processo de emancipação, bem como propiciar mudanças em sua família. A operacionalização deste projeto intenciona contribuir para a implementação de políticas públicas voltadas para as mulheres, a partir do entendimento de que o trabalho com este recorte de gênero em especial requer mais ações que atendam as demandas que já se apresentam e as demais que vão surgindo no cotidiano. Neste sentido, vale lembrar que esse processo de formação inclusiva tende a contribuir positivamente para que jovens e adultas trabalhadoras, desempregadas e/ou subempregadas, superem suas condições precárias de vida, sendo capazes de imprimir a suas vidas a merecida mobilidade social, a qual, certamente, Ihes trará melhores condições de vida. Implantado no Campus Codó-MA, o Programa Mulheres Mil está inserido no rol de obrigações institucionais consagradas em Legislação Federal e no ordenamento jurídico do Instituto Federal de Educação, Ciência e Tecnologia do Maranhão, como uma de suas áreas temáticas de atuação. 
O Programa Mulheres Mil desenvolvido no Campus Codó-MA fornece as ferramentas e os caminhos às mulheres em situação de vulnerabilidade social, de algumas comunidades do município de Codó-MA, a exemplo de: Codó Novo, Barra do Saco, Santa Filomena, São Pedro, São Sebastião, Nova Jerusalém, Santa Terezinha entre outras. Mulheres essas com perfis diversos e difusos, pois na sua maioria são domésticas, costureiras, artesã, extrativistas, lavradoras e muitas vivenciam em seu cotidiano a violência doméstica perpetrada por seus companheiros e /ou ex- companheiros.

Dentro dessa estimativa, muitas mulheres perdem sua identidade social: são as "MARIAS" tão somente, dentre tantas outras. Espera-se que, com as diretrizes estabelecidas pelo Programa Mulheres Mil, mediante desenvolvimento de um trabalho balizado pelos eixos da Educação, Cidadania e Desenvolvimento Sustentável, haja o crescimento pessoal/profissional e elevação da auto-estima dessas mulheres, a fim de que elas possam assumir seu papel e lugar social, com identidade própria, com voz e vez, conforme preconiza a denominação do Projeto. Nesse cenário, o Programa Mulheres Mil apresenta-se como uma possibilidade concreta de valorização de formação profissional e elevação da empregabilidade, através de uma perspectiva de sustentabilidade social, que está ligada intimamente à ideia de garantia direitos e melhoria da qualidade de vida dessas cidadãs.

\section{A violência contra a mulher}

Segundo Grossi (2001, p. 71), violência, em seu significado mais frequente, é aquilo "que fere, destrói ou agride as pessoas, ações que não preservam a vida e/ou prejudicam o bem-estar individual quanto social". Para Teles e Melo (2012), violência é o uso da força física, psicológica ou intelectual para obrigar a outra pessoa a fazer algo contra a sua vontade; é impedir a outra pessoa de manifestar seu desejo e sua vontade; É um meio de manter a outra pessoa sob seu domínio. Constitui-se ainda como "uma violação aos direitos humanos e um obstáculo para a cidadania de milhares de mulheres" (SAFFIOTI, 1997, p. 8).

A violência contra as mulheres apresenta-se de diversas formas, dependendo da cultura, e as estratégias de enfrentamento também são distintas em cada sociedade. Para May (1972) a violência ocorre quando uma pessoa não pode vivenciar de maneira normal as suas necessidades de poder. Saffioti (2015) define a violência como ruptura de qualquer forma de integridade da vítima, seja de forma física, psíquica, sexual ou moral. É nessa ambiência que se encontra a violência contra a mulher, também tratada como violência de gênero e violência doméstica.

Segundo Saffioti (2015), a violência doméstica, aquela ocorrida no âmbito doméstico, apresenta características específicas. Uma das mais relevantes é a sua rotinização, ou seja, ela acontece sobre as mesmas vítimas, tornando-se rotineira: os agressores são geralmente 
maridos, companheiros ou ex-maridos e ex-companheiros das vítimas; as agressões sofridas não são conhecidas até transcorrer um longo período de tempo; as vítimas possuem autoestima baixa e podem apresentar vários problemas de saúde, na maioria dos casos, as mulheres são chantageadas e/ou ameaçadas, sentindo-se incapazes de reagir; as vítimas vivem em estado de pânico e temor.

Para melhor compreensão apresentam-se pequenas vinhetas baseadas nas narrativas de mulheres como Maria de Fátima ${ }^{4}$, Maria Rejane, Maria Nice e Maria Penélope alunas do Programa Mulheres Mil que dividiram suas histórias de vidas. Em suas falas percebe-se que foram vítimas das diversas formas de violência.

Eu não tinha mais vontade de me arrumar. Ele [parceiro] nunca me elogiava[...] me chamava de gorda e isso fazia minha autoestima ficar baixa...quase não me olhava no espelho. Não gostava de ver minha imagem. Também fui perdendo de gostar dele. Não me sentia feliz no relacionamento. Tudo ele botava defeito, viu. Na comida, na casa, na roupa que eu lavava. Ele só sabia me humilhar. (MARIA DE FÁTIMA, 32 anos).

Ele é o pai de meus filhos! Sabe como é né... acho que fui aprendendo a tolerar, a suportar os xingamentos deles, as humilhações. Me chamava de tudo. Me chamava de vagabunda, de rapariga, que eu não servia pr'a ele. Dizia que eu tinha macho na rua. Escutei muita coisa, Professora. E tudo na frente das crianças ou de qualquer que um que tava na casa. Eu não podia fazer nada. Às vezes me sinto um nada. É triste dizer, isso, Professora, mais é o que eu acho e sinto. (MARIA REJANE, 40 anos).

Ele falava assim, ele dizia que eu não tinha juízo. Ele falava assim: o que eu imaginava, o que eu esperava dele, que ele ia largar a família dele para ir viver com uma caipira, que eu era do interior, que eu era burra, que estava me enchendo de filhos, que ele não queria nada sério comigo. Me abalava, isso aí me magoava muito né, porque o que eu queria não era isso, era criar os meus filhos com ele, não importava a diferença de idade, apesar dele ser mais velho do que eu, mas o meu pensamento era isso. (MARIA NICE, 42 anos).

Ele queria me moldar na forma que ele achava correto, mulher não sorrir alto desse jeito, rir direito, mulher não dar gargalhada, quem rir assim é puta, quem rir desse jeito é puta, senta direito, quem senta assim é puta! Ele queria que eu fosse uma princesinha, quanto na verdade eu não era essa princesinha, eu era aquela mulher que chegava tomava cerveja, puxava conversa, eu não sou tão expansiva, eu sou uma pessoa tímida, mas se eu fizer amizade, eu vou conversar sobre tudo, eu faço amizade com homem, que eu gosto muito de conversar com homem, para ele isso é inadmissível, porque eu tinha que conversar com as meninas, conversar com homem de jeito nenhum, porque ele tinha ciúme, tomar cerveja, deus que me livre! cerveja era coisa de puta, fumar, que eu já cheguei a fumar algumas vezes na frente dele, que era feio, era ridículo fumar, tanto que hoje eu não sou fumante, porque ele nunca deixou. (MARIA PENÉLOPE, 32 anos).

As consequências da violência psicológica estão muito presente na fala de Maria de Lourdes e de Maria Débora bem como os agravos na sua saúde emocional, fica evidenciado nos trechos a seguir:

4 Todos os nomes utilizados são fictícios. 
Ele [companheiro] me agredia muito verbalmente, me chama de muitas palavras que me dói por dentro. Sei que não sou isso que ele diz. Mais de tanto ele me chamar desses nomes ruins, feios eu já estava acreditando que eu era tudo isso que ele me chamava. Às vezes mandava ele me bater mesmo, não que eu gostava de apanhar dele, porque me batendo ia sofrer menos que ouvir ele me chamar desses nomes, desses palavrão, era muito palavrão. Dormia e acordava pensando nas palavras feias que ele me chamava...Parece que grudava na minha mente...e não ia embora da minha cabeça. (MARIA DE LOURDES, 38 anos).

Uma das grandes consequências que me trouxe, foi que afetou a minha saúde, eu não tinha problema de pressão alta, minha pressão hoje é alta, eu tento controlar na medida do possível, porque por essas agressões que eu passei de várias formas, afetou o meu emocional, a minha memória. Eu fiquei esquecida, para mim fazer uma coisa eu tenho que ficar fazendo um esforço para lembrar, se eu falar uma coisa, de manhã, se eu não anotar, à tarde não estou conseguindo muito lembrar, fico forçando a mente. Tudo meu hoje é anotado, porque eu fiquei com as consequências desse relacionamento, que até então eu não sentia esse problema. E também perdi um pouco a vontade de me alimentar, eu era uma pessoa que gostava muito de fruta assim, verduras, eu sempre gostei, porque eu fui criada em um sítio, hoje eu não tenho muita vontade de comer fruta. (MARIA DÉBORA, 46 anos).

Diante desses depoimentos é notório o quanto a violência emocional deixa suas marcas e sequelas nas vidas de mulheres vítimas de violência. O que se observa é que a violência emocional tem permanecido secundarizada. Miller (1999, p. 40), ancorada em seus estudos sobre Violência Psicológica, ressalta:

O corpo resiliente recupera-se com ungüentos e talas - as mulheres espancadas sabem disso em sua dor. Mas o sofrimento do espancamento emocional é tão profundo, a angústia é tão intensa, a recuperação tão intangível que, como diz o ditado espanhol, 'aquele que perde o espírito, perde tudo'. A mulher objeto de abuso emocional perde a si mesma.

Miller (1999), ainda destaca que a violência não física pode ser classificada como: abuso emocional, abuso psicológico, abuso social e abuso econômico. É válido ressaltar, que essas manifestações de violência expressa pela autora foram identificadas na pesquisa.

Segundo Heise (1994), há uma estimativa, no Brasil, de que a cada ano 300.000 mulheres são vítimas de seus maridos ou companheiros. Também estudos e pesquisas encomendadas pelo Ministério da Saúde e pela Organização das Nações Unidas (ONU) apontam que a violência contra a mulher atinge milhares de brasileiras dentro do próprio lar, tendo o cônjuge/companheiro como o agressor.

Em termos gerais a violência doméstica consiste no abuso físico, sexual, emocional e patrimonial praticado por pessoas que convivem no mesmo domicílio, independentemente da existência de parentesco, sendo, na maioria das vezes, praticada contra a mulher na relação conjugal. No que tange a violência doméstica ser ou não uma "questão menor", da "esfera privada", Barsted (1997, p. 73-74) menciona com muita propriedade que: 
[...] pensar que a violência conjugal não ameaça a ordem é esquecer que, quando um indivíduo está imbuído do papel de justiceiro ao agredir ou matar sua mulher, porque ela deixou de fazer a comida, não chegou cedo em casa, enfim, resolveu desobedece-lo, esse indivíduo está difundindo um modelo perigoso à ordem pública. A pouca importância dada aos crimes cometidos no espaço doméstico pode levar ao entendimento de que existe uma lei privada, uma lei interna às famílias que permite que pais castiguem filhos até a brutalidade e que maridos e companheiros castiguem suas mulheres porque elas não correspondem ao papel de esposas ou de mães tradicionais. Esses homens que fazem e aplicam essa lei privada são os famosos 'justiceiros'.

Segundo Grossi (1994, p.41), "a violência contra a mulher se manifesta de diferentes formas na nossa sociedade, desde o plano simbólico, que estabelece papéis sociais impostos, até a violência física". A primeira se refere a violência visível, que é a mais fácil de ser identificável, por deixar suas marcas, podendo se revelar-se de diferentes formas como: a violência física e a violência sexual; e a segunda que é a invisível, que não deixa marcas, lesões no corpo, mas é manifestada por meio da violência emocional que pode ser trajada como: isolamento, falta de autoestima, desvalorização cotidiana, intimidação, dominação, entre outras.

\subsection{As Vozes de Mulheres Vítimas de Violência Doméstica atendidas no Mulheres Mil}

De acordo com a Organização Mundial de Saúde (OMS) a violência doméstica é reconhecida como um problema de saúde pública, uma vez que afeta a integridade física e a saúde mental da mulher. Aborda-se nesse artigo o tema da violência contra a mulher, perpetrada por parceiros íntimos, isto é quando acontece entre o casal, na intimidade e segurança do "lar", pois segundo o relatório da Organização Mundial de Saúde (OMS) no que se refere a violência, assim discorre:

Uma das formas mais comum de violência contra as mulheres é a praticada por um marido ou um parceiro íntimo. [...] $O$ fato de as mulheres em geral estarem emocionalmente envolvidas com quem as vitimiza, e dependerem economicamente deles, tem grandes implicações tanto para a dinâmica do abuso quanto para as abordagens para se lidar com isso. (KRUG et al., 2002, p. 91).

Diante das várias acepções sobre violência doméstica, é notório dizer que esses conceitos são carregados de uma abrangência que vai além de nossas interpretações, possuindo variadas expressões que no dizer de Strey (2001, p. 23):

A violência doméstica, pelo seu envolvimento, em grande parte dos casos, com relações familiares e o espaço do domicílio, é caracterizada como uma questão relativa estritamente à esfera da vida privada, encoberta também pela ideologia que apresenta a família como uma instituição natural, sagrada, na qual se desenvolvem apenas relações de afeto, carinho, amor e proteção, a ser preservada pela sociedade. 
Almeida (2007, p. 48) contribui para esclarecer o conceito ao afirmar:

Violência doméstica é uma noção espacializada, que designa o que é próprio à esfera privada - dimensão da vida social que vem sendo historicamente contraposta ao público, ao político. Enfatiza, portanto, uma esfera da vida, independente do sujeito, do objeto ou do vetor.

$\mathrm{Na}$ violência doméstica contra a mulher, o abuso pelo parceiro pode tomar várias formas, tais como: agressões físicas, abuso psicológicos como menosprezo, intimidações e humilhações constantes, coerção sexual, comportamentos de controle, como por exemplo, proibição de contato com a família e amigos, usar os filhos para fazer chantagem, vigilância constante e restrição de acesso e recursos variados. Esse tipo de violência traz consequências gravíssimas para as vítimas, que vão muito além das lesões corporais.

Ele [companheiro] não era um homem violento quando eu conheci. Ele era calmo, manso. Mais com o tempo se transformou em um homem violento, raivoso. Quando chega bêbado quebra tudo em casa, reclama, faz xingamentos e me ameaça. As pessoas mandam eu me separar. Mais eu não tenho onde morar. [..] a casa é dele. Se eu pudesse ia embora com minhas crianças. (MARIA LOURDES, 38 anos).

Eu me via como uma pobre coitada, eu já usei este termo, vou usar novamente, estava refém de relacionamento abusivo e eu me via como uma pessoa fracassada que tinha parado de estudar, não estava ainda na faculdade, só cuidado de menino, eu tinha uma revolta imensa porque eu sempre tive planos e eu não estava conseguindo cumprir, mas realmente parei de estudar por um tempo e eu tinha essa revolta por não trabalhar também e nem estudava, nem tralhava e foi uma situação inusitada, que eu nunca esperei que fosse acontecer comigo que era ficar em casa e como eu expliquei, numa casa que não era minha, onde eu não resolvia nada, onde eu tive que me adaptar a uma outra família né, e cuidar de um bebê só isso para mim, eu me sentia presa àquela criança e a um relacionamento que não me elevava, não me fazia bem. (MARIA BEATRIZ, 38 anos).

Eu não me sentia valorizada por ele. Eu sabia que ele me achava bonita, me achava atraente, mas não conseguia me sentir valorizada, não conseguia me sentir amada, eu falei que o mais me incomodava era o fato dele não ser carinhoso, pois o que mais me incomodava era fato de eu não me sentir amada perto dele, parecia que ele estava, ali meio sei lá, pelas circunstâncias, porque a gente namorou muito tempo, teve que casar, talvez por isso a minha autoestima não era muito boa, eu não me sentia feia, mas também não tinha aquela vontade de me arrumar e me olhar no espelho, nossa que mulher bonita eu sou! Não me sentia bem para me arrumar, para sair. (MARIA PENÉLOPE, 32 anos).

Vários são os fatores que contribuem para a permanência na situação de violência que atingem essas mulheres, ou seja, o agravante da dependência econômica, o desemprego por parte da mulher, a dependência emocional e outras diversas condições desfavoráveis fortalecem essa realidade e a permanência na relação. Esses fatores são determinantes e dificultam o registro e o real dimensionamento da violência contra mulher. Uma vez que, não se rompe com o ciclo da invisibilidade e do silêncio. 
Eu nunca larguei dele porque não tenho onde ficar. E morar com meus pais de novo é ruim. Eles [os pais] falam que eu casei com um homem irresponsável, vagabundo e que nunca me respeitou. Sofro muito em viver com um homem assim. Deixei o trabalho para cuidar dos filhos e da casa. $E$ não sei se foi uma coisa boa pra mim. Dependo dele em tudo. (MARIA REJANE, 40 anos).

O problema é que a gente não tem pra onde ir. Vou morar aonde? Com esses filhos? A casa é dele. 'Joga' isso todos os dias na minha cara quando briga comigo. Se eu tivesse condições, eu me separava dele, ele é muito agressivo. (MARIA DE FÁTIMA, 32 anos).

Outro fator decisivo para que a violência doméstica seja pouco denunciada é a manutenção do segredo familiar vinculado à honra ou à situação de provedor da família do agressor (SAFFIOTI; ALMEIDA, 1995). A dificuldade em efetuar a denúncia é uma realidade evidenciada nos depoimentos a seguir:

[...] Eu apanhei muito desse homem [parceiro], quantas vezes eu apanhei... Nunca pensei que teria essa vida sofrida, amarga. Não tinha coragem de denunciar. Pensava: 'o que os outros vão pensar'? Todo mundo ia saber que eu apanhava do meu parceiro. Como ia ser minha vida? Tive medo. Fui covarde demais, Professora. Hoje sem que perdi tempo com esse homem ao meu lado. Que nunca foi um companheiro de verdade. Sinto que errei e nem sei se um dia vou refazer minha vida de novo. Queria fazer diferente. (MARIA DE FÁTIMA, 32 anos).

Mas quando ele brigava comigo, muitas vez, ele me ameaçava que ia me matar e matar as crianças. Sempre tive muito medo dele. Não tinha forças para ir numa Delegacia, dar uma queixa, dizer pr'o Delegado o que acontecia comigo. Tinha muito medo de acontecer algo com as crianças. Com os próprios filhos dele. (MARIA DE LOURDES, 38 anos).

Sofri muito tempo calada. Não contava pra ninguém que apanhava do marido. E achava que ninguém sabia também. Fui muito ingênua em acreditar nisso. As pessoas me olhavam na rua já me condenando. Fui aguentando calada. Não sabia nem porque eu apanhava, viu. Acho que dava a doida nele. Chegava bêbado em casa e queria quebrar tudinho. Nunca pisei numa Delegacia para dizer que ele me batia. Deveria ter ido. Talvez, alguma coisa seria feita, não é mesmo! (MARIA REJANE, 40 anos).

No entanto, muitas mulheres ainda deixam de prestar queixa contra o agressor e outras não reconhecem a situação vivida como violência. Também pode ocorrer de as mulheres se sentirem envergonhadas e culpadas pela agressão sofrida, passando a ocultar os fatos (MONTEIRO; SOUZA, 2007). Romper com o fenômeno da violência doméstica nas relações conjugais constitui-se um desafio para a atualidade, mostrando-se

[...] necessário que exista uma rede articulada de apoio à mulher agredida que atenda às suas necessidades: para compreender o porquê de a mulher permanecer com quem a agride, torna-se necessário desvelar essa realidade oculta que oprime cotidianamente a mulher e a mantém no pólo da subordinação. (CARDOSO, 1997, p. 136). 
Diante desse quadro de referência afirma-se que a violência contra a mulher perpetrada nas relações conjugais está inserida em uma teia de relações sociais, institucionais e culturais que reproduzem o modelo patriarcal vigente.

\section{Considerações finais}

Os relatos aqui expostos demonstram a resistência e a coragem de sete mulheres que de alguma forma tornaram visíveis suas vozes. Romperam com o silêncio e com a invisibilidade que assombravam suas vidas. Romper as barreiras do silêncio e da invisibilidade do fenômeno da violência contra a mulher na esfera das relações afetivas implica a mobilização de todos os setores da sociedade, ou seja, uma profunda mudança dos estereótipos de gênero construídos socialmente e que ainda hoje carrega raízes densas na sociedade. Esses depoimentos são de mulheres que já haviam se separado dos seus companheiros e uma em processo de separação até o momento da pesquisa. Acreditando em um futuro seguro cheio de possibilidades e muitas delas retomaram suas vidas a partir da educação. Voltaram a estudar na intenção de conquistar uma vida melhor.

Nessa perspectiva, urge a necessidade de rompermos o silêncio frente à violência sofrida nos lares, entre as quatro paredes e sensibilizar a sociedade para a inserção da temática da violência contra a mulher nos currículos escolares e na formação de diferentes profissionais. As narrativas orais das mulheres participantes deste estudo refletem que houve uma transformação substantiva na vida pessoal e familiar, como sujeitos da sua própria história. Há casos em que os filhos voltaram a estudar porque queriam seguir o exemplo da mãe; outras já garantem a renda familiar com a própria produção etc. Os primeiros resultados esperados já apontavam para o caminho da institucionalização da experiência como política pública inovadora, na qual a educação e a formação profissional e tecnológica se consolidam como instrumento para a inclusão de mulheres que estão à margem da sociedade.

Os resultados obtidos nessa experiência demonstram a importância de implantar políticas educacionais com recorte de gênero. Segundo narrativas orais das alunas, detectouse que o acesso à formação educacional e profissional contribuiu para mudanças na vida dessas mulheres em diversos aspectos, desde a inserção de egressas no mundo do trabalho, nas relações familiares, na melhoria do desempenho dos seus filhos na escola, visto que elas passaram a auxiliá-los e incentivá-los nos estudos. Além disso, elas conquistaram respeito dos seus familiares e/ou companheiros e ex-companheiros, reduzindo a violência doméstica, assim como assumiram o papel de mulheres empoderada frente a situação que viviam e incentivando e mobilizando outras mulheres a seguir a mesma trajetória. 


\section{Agradecimentos}

Agradeçemos a todas as mulheres que compartilharam suas histórias de vidas nesse trabalho. Agradeço ao Instituto Federal de Educação, Ciência e Tecnologia do Maranhão Campus Codó pelo incentivo em Qualificação Profissional e por proporcionar a Participação no VII Simpósio Internacional Trabalho, Relações de Trabalho, Educação e Identidade (Sitre).

\section{Referências}

ALMEIDA, Suely de Souza. Violência de gênero e políticas públicas. Rio de Janeiro: Editora da UERJ, 2007.

BARSTED, Leila Linhares. Metade vítimas, metade cúmplices? A violência contra as muIheres nas relações conjugais. Porto Alegre: Sulina, 1997.

BRASIL. Lei no 11.892, de 29 de dezembro de 2008. Institui a Rede Federal de Educação Profissional, Científica e Tecnológica, cria os Institutos Federais de Educação, Ciência e Tecnologia, e dá outras providências. Diário Oficial da União, Brasília, DF, 30 dez. 2008. Disponível em: <http://www.planalto.gov.br/ccivil_03/_ato2007-2010/2008/lei//11892.htm>. Acesso em: 20 dez. 2017.

Ministério da Educação. Portaria no 1.015, de 21 de julho de 2011. Instituir o Programa Nacional Mulheres Mil que visa à formação profissional e tecnológica articulada com elevação de escolaridade de mulheres em situação de vulnerabilidade social. Diário Oficial da União, Brasília, DF, n. 140, 22 jul. 2011b. Seção 1. Disponível em: <http://portal.mec.gov.br/index.php?option=com_docman\&view=download\&alias=8589portaria1015-220711-pmm-pdf\&Itemid=30192>. Acesso em: 20 dez. 2017.

Ministério da Educação. Programa Nacional Mulheres Mil: educação, cidadania e desenvolvimento sustentável. 2011. Brasília, DF, 2011a. Disponível em: $<$ http://portal.mec.gov.br/index.php?option=com_docman\&view=download\&alias=8598programa-mulheres-mil-110811-pdf\&category_slug=agosto-2011-pdf\&ltemid=30192>. Acesso em: 20 dez. 2017.

CARDOSO, Nara Maria Batista. Psicologia e relações de gênero: a socialização do gênero feminino e suas implicações na violência conjugal em relação às mulheres. In: ZANELLA, Andréa et al. (Orgs.). Psicologia e práticas sociais. 19. ed. Porto Alegre: Abrasposul, 1997. p. 280-292.

CONSELHO NACIONAL DE ASSISTÊNCIA SOCIAL. Resolução ํㅜ 109, de 11 de novembro de 2009. Aprova a Tipificação Nacional de Serviços Socioassistenciais. Diário Oficial da União, Brasília, DF, n. 225, 25 nov. 2009. Seção 1.

GIL, Antonio Carlos. Métodos e técnicas de pesquisa social. 6. ed. São Paulo: Atlas, 2010. 
GROSSI, Patrícia K. Violência contra a mulher na esfera doméstica: rompendo o silêncio. 1994. 238 f. Dissertação (Mestrado) - Pontifícia Universidade Católica do Rio Grande do Sul, Porto Alegre, 1994.

. Violências e gênero: coisas que a gente não gostaria de saber. Porto Alegre: EDIPUCRS, 2001.

HEISE, Lori. Gender based abuse: the global epidemic. Cadernos de Saúde Pública, Rio de Janeiro, v. 10, n. 1, p. 135-145, 1994.

KRUG, Etienne G. et al. (Eds.). Relatório mundial sobre violência e saúde. Genebra: OMS, 2002. Disponível em: <https://www.opas.org.br/wp-content/uploads/2015/09/relatoriomundial-violencia-saude.pdf>. Acesso em: 20 dez. 2017.

MAY, Rollo. Poder e inocência. Editora: Artenova, 1972.

MILLER, Mary Susan. Feridas invisíveis: abuso não físico de mulheres. São Paulo: Summus, 1999.

MONTEIRO, Claudete Ferreira de Souza; SOUZA, Emília de Oliveira. Vivência da violência conjugal: fatos do cotidiano. Texto \& Contexto Enfermagem, Florianópolis, v. 16, n. 1, p. 1631, jan./mar. 2007.

ORGANIZAÇÃO DOS ESTADOS AMERICANOS. Convenção Interamericana para Prevenir, Punir e Erradicar a Violência Contra a Mulher, "Convenção de Belém do Pará". Belém, 1994. Disponível em: <http://www.cidh.org/basicos/portugues/m.belem.do.para.htm>. Acesso em: 10 mar. 2017.

ROSA, Stela. (Org.). Mulheres mil: do sonho à realidade. Stela Rosa. Brasília, DF: Ministério da $2011 . \quad$ Disponível em: <http://mulheresmil.mec.gov.br/images/stories/pdf/geral/livro_mulheres_mil_portugues.pdf>. Acesso em: 20 dez. 2017.

SAFFIOTI, Heleieth lara Bongiovani. Gênero, patriarcado, violência. São Paulo: Editora Fundação Perseu Abramo, 2015.

Violência doméstica ou a lógica do galinheiro. In: KUPSTAS, Márcia (Org.). Violência em debate. São Paulo: Editora moderna, 1997. p. 39-57.

SAFFIOTI, Heleieth lara Bongiovani; ALMEIDA, Suely de Souza. Violência de gênero: poder e impotência. Rio de Janeiro: Revinter, 1995.

STREY, Marlene Neves. Violência e gênero: um casamento que tem tudo para dar certo. In: GROSSI, Patrícia. Violência e gênero: coisas que a gente não gostaria de saber. Porto Alegre: EDIPUCRS, 2001. p. 47-69.

TELES, Maria Amélia de Almeida; MELO, Mônica de. $\mathbf{O}$ que é violência contra a mulher. São Paulo: Brasiliense, 2012. (Coleção Primeiros Passos). 